\title{
Valuable, rare, inimitable resources and organization (VRIO) resources or valuable, rare, inimitable resources (VRI) capabilities: What leads to competitive advantage?
}

\author{
Nuno Cardeal ${ }^{1 \star}$ and Nelson António ${ }^{2}$ \\ ${ }^{1}$ Católica-Lisbon School of Business Economics, Universidade Católica Portuguesa, Palma de Cima, Lisbon, Portugal. \\ ${ }^{2}$ ISCTE-IUL Lisbon, Av. Forças Armadas, Lisbon, Portugal. \\ Accepted 13 July, 2012
}

\begin{abstract}
The resource-based view (RBV) argues that valuable, rare, inimitable resources and organization (VRIO) lead to competitive advantage. Dynamic capabilities (DC) are a comparatively new field and the related literature is mainly conceptual. Capabilities can be considered as the firm's routines and processes. We argue that the "O" in VRIO refers to DC. DCs are the "organization" needed to transform bundles of resources into competitive advantage. Consequently, does competitive advantage stem from VRIO resources or from VRI capabilities? Through a case study we analyzed the development of one capability in a medium-sized Portuguese footwear manufacturer. After reviewing the process of development of the capability, we performed a VRIO test for each of the resources it exploits and a VRI test of the capability. We can conclude that none of the resources contributing to the capability are VRIO, but the capability is VRI.
\end{abstract}

Key words: Competitive advantage, dynamic capabilities, footwear, resource-based view.

\section{INTRODUCTION}

The resource based view (RBV) focuses on specific resources and highlights that competitive advantage is based on valuable, rare, inimitable resources and organization (VRIO) (Barney, 1997). Dynamic capabilities (DC), which represent the firm's behavioral orientation towards constant integration, reconfiguration, renewal and recreation of its resources and capabilities and continuous upgrading and reconstruction of its core capabilities in response to the changing environment and to remain competitive (Wang and Ahmed, 2007), focus on internal processes or routines.

The RBV does not explain how competitive advantage is achieved (Priem and Butler, 2001a). The DC view explores how the firms' resources and capabilities evolve over time and provides a better understanding of how

*Corresponding author E-mail: nucard@ucp.pt. Tel: +351 217 214000. competitive advantage is achieved and maintained (Ambrosini and Bowman, 2009). The DC literature is quite new, which is probably the reason why it is mostly conceptual and provides little empirical evidence, on how to overcome the shortcomings of the RBV (Priem and Butler, 2001a).

We provide an extensive review of the state of the art of the RBV and DC literatures. We conclude that from the RBV viewpoint, to have a competitive advantage, firms need to have VRIO resources. The unit of analysis is the resource. On the other side, from the DC viewpoint, capabilities in the origin of the competitive advantage need to be VRI (being "O" the capability itself). The unit of analysis is the "O". Then we argue that DC can be seen as the "O" in VRIO according to the RBV. Being DCs the VRIO's "O", to achieve competitive advantage, firms need to have VRI (valuable, rare and inimitable) capabilities. If we compare the RBV and the DC literature, a tension emerges about whether competitive advantage stems from VRIO resources or from VRI capabilities. 
We use a case-study methodology to analyze the development of one capability by a medium sized Portuguese footwear manufacturer. We deeply analyzed the way the firm renewed, recreated, upgraded and reconstructed its resources / capabilities in response to the changing environment. After reviewing the process of developing the capability, we test its inputs for VRIO and test the capability for VRI. We find that competitive advantage stems from the VRI capability. We adopt the definition of firm competitive advantage as creating more economic value than a marginal competitor that achieves only break-even (Peteraf and Barney, 2003).

This present study makes several contributions. First, it provides an in depth analysis of how the capability that provides the case firm with its competitive advantage was developed. This has implications for both managers and scholars/researchers. Second, the findings on VRI DC vs. VRIO RBV highlight some of the limitations of the resource literature concerning the creation of competitive advantage.

\section{LITERATURE REVIEW}

\section{Resource based view (RBV)}

Barney (1991) is generally acknowledged as the first scholar to develop the theoretical tool explanatory of RBV (Newbert, 2008). To have the potential to create sustainable competitive advantage, a resource must be valuable, rare, inimitable and non-substitutable (VRIN). In the present study, a firm is deemed to have competitive advantage when it creates more economic value than its marginal competitor (Peteraf and Barney, 2003).

Contrasting with VRIN, Peteraf and Barney (2003) suggest that competitive advantage results from the existence of critical resources that are used in a superior way. The "higher use" of these resources is aligned to a new approach that responds to concerns over how resources are transformed into competitive advantage: VRIN resources if managed by unskilled people, unable to evaluate their usefulness and/or benefits, or to make appropriate use of them, will provide no benefit to the firm (Katkalo et al., 2010). VRIO considers that it is through the firm's internal organization that resources are transformed into competitive advantage (Barney, 1995, 1997). But what is this "organization"? The existing RVB literature does not properly address this question. Organization is seen as "something else".

Barney (1991) repeatedly uses the term "resource bundles", resulting in references to integration of resources; in VRIN, the emphasis is on the resource level. In VRIO, the emphasis moves downstream to the functionality and/or usefulness of the resources. However, the unit of analysis is still the resource. Thus, although the resource may be valuable, rare and difficult to imitate, if there are any strategically equivalent resources that are not rare or difficult to imitate, then the focal resource cannot be the source of competitive advantage (Barney, 2001).

\section{Dynamic capabilities (DC}

The DC literature (Adner and Helfat, 2003; Eisenhardt and Martin, 2000; Helfat et al., 2007; Makadok, 2001; Teece et al., 1997; Zollo and Winter, 2002) tries to explain how companies renew their existing capabilities and resources to adapt to the changing business environment.

So far, the DC literature has focused on conceptual research which has very little empirical support (Ambrosini and Bowman, 2009; Barreto, 2010; Di Stefano et al., 2010; Wu, 2010). The few empirical support often do not address the origins of capabilities development (Felin and Nicolai, 2009). The lack of consensus on DC (Arend and Bromiley, 2009; Prieto et al., 2009) has led to alternative definitions (Barreto, 2010; Døving and Gooderham, 2008; Eisenhardt and Martin, 2000; Teece et al., 1997; Wang and Ahmed, 2007; Winter, 2003; Zahra et al., 2006).

In the DC perspective, and in contrast to the RBV, the distinction between resources and capabilities is very clear. The sources of competitive advantage lie in the context of DC, with greater emphasis on capabilities than on resources because the value of resources in the context of dynamic markets tends to depreciate quickly (Collis and Montgomery, 2008). Resources remain important, not per se, but based on the configuration conferred by DC (Cavusgil et al., 2007; Liao et al., 2009; Morgan et al., 2009; Prieto et al., 2009), because it is not clear that all companies use their resources in the same ways, even those resources that are easily accessible. Instead, firms combine these resources with inside knowledge, in order to put together the pieces of a puzzle, to find solutions, and to achieve strategic and operational objectives. The way these resources are interconnected and the most appropriate combinations and types of interconnections are relevant in DC (Kay, 2010).

As important as having useful resources is the possession of capabilities, that allows the integration and use of these resources (Barney and Wright, 1998; Newbert, 2008). Thus, a capability can be seen as the "O" in VRIO - the way the firms organize a bundle of resources.

\section{VRIO RBV vS. VRI DC}

\section{Value}

The resource creates value when it allows the company to devise and implement strategies that will improve its efficiency and effectiveness. Departing from the 
traditional strengths, weaknesses, opportunities and threats (SWOT) analysis, an attribute creates value and becomes a resource if it enables the exploitation of opportunities and/or the neutralization of threats (Barney, 1991). Penrose (1959) identified resources as bundles of potential services. She also defined services as the result of how the company uses its resources; they are not useful unless they are used efficiently. For Amit and Schoemaker (1993) companies must have access to adequate capabilities to take advantage of their resources. That is, while certain resources may have the potential to create valuable services, the value of these services will remain latent until the firm has the capabilities needed to deploy them (Newbert, 2008). This is consistent with several other definitions of resources, for example, resources are valuable when they contribute to the production of something customers want, at a price they are willing to pay (Collis and Montgomery, 1995); valuable resources enable the firm to do things that lead to economic value (Fiol, 1991); valuable resources have some capacity to generate profits and prevent losses (Miller and Shamsie, 1996). Words, such as "enable", "contribute" or "some capacity" point to the need for something else to transform the (valuable) resource into the output that provides value. In an attempt to operationalize the concept of valuable resources, Bowman and Ambrosini (2007) define resources in the broad sense, to include activities and capabilities. Thus, by themselves, resources cannot be valuable (enablers of the exploitation of opportunities and/or blockers of the negative effects of threats).

\section{Rareness}

If most competitors hold the same valuable resource, then they will likely explore their use in similar ways, thus implementing the same value creating strategy. This would not result in any company achieving competitive advantage as a result of owning a valuable resource (Barney and Zajac, 1994).

\section{Inimitability}

If valuable and rare resources are easily imitable, competitors would quickly copy them and the potential for competitive advantage would disappear. Resources tend to be more difficult to imitate if: (a) they are path dependent (Dierickx and Cool, 1989; Vergne and Durand, 2011); (b) there is an ambiguous relationship between the resources that enhances competitive advantage (Barney, 1995; Dierickx and Cool, 1989; Reed and DeFillipi, 1990); (c) they are socially complex, for example, if they are beyond the ability of firms to manage and manipulate them in a systematic way (Barney, 1991); (d) there are legal property rights, such as in the case of patents (Wills-Johnson, 2008); (e) the process of their imitation by other companies is lengthy, for example due to the time needed to train employees or to absorb the knowledge necessary to master the resource (WillsJohnson, 2008).

\section{Organization}

Competitive advantage stems from the way firms operate and interrelate their strategic and non-strategic resources (Pan et al., 2007), exploiting organizational processes, to produce what can be regarded as intermediate products between primary resources and the firm's final products (Amit and Schoemaker, 1993).

The DC literature provides a rich hierarchy of capabilities. For example, Collis (1994) argues that there are first, second and third order, as well as Meta, and ad infinitum Meta capabilities. Danneels (2002) proposes two levels of capabilities (first and second order). Winter (2003) proposes the existence of zero-level, first order and higher order capabilities while Zahra et al. (2006) classify capabilities as substantive and dynamic. They have been described also as incremental, renewal and regenerative (Ambrosini et al., 2009), or operational capabilities, portfolios of capabilities and constellations of capabilities (Laamanen and Wallin, 2009), or as still capabilities and core capabilities (Wang and Ahmed, 2007). Given the discussion around these hierarchies of capabilities, we propose that capabilities are organizational processes (skills, expertise, know-how, management) firms use to explore their resources and lower level capabilities in the conduction of day-to-day operations. They are intermediary outputs between resources and lower level capabilities (inputs), and final products (outputs). DC is defined as capabilities that endow firms with competitive advantage in changing environments. Both capabilities and DC are "organization". A DC is the VRIO's "O". To be a source of competitive advantage it must be VRI.

Over time, firms have opportunities to improve their organizational processes or routines (which reflect how things are done in the company). Combining this path dependency effect with the fact that, due to their strong intangible component, organizational resources or routines are ambiguous (in the sense that their relationship with competitive advantage is not evident and is often the result of the integration of various packages of resources) and are also socially complex, these processes/routines are difficult for competitors to imitate, which increases the firm's potential to achieve competitive advantage (Teece et al., 1997).

These issues of ambiguity, path dependency and intangibility are so complex that despite having mastered the capabilities firms view them as ambiguous and mysterious (Lado and Wilson, 1994; Reed and DeFillipi, 1990). However, firms that develop better ways of integrating their resources have more and stronger sources of competitive advantage.

To summarize, from the RBV, to achieve competitive 


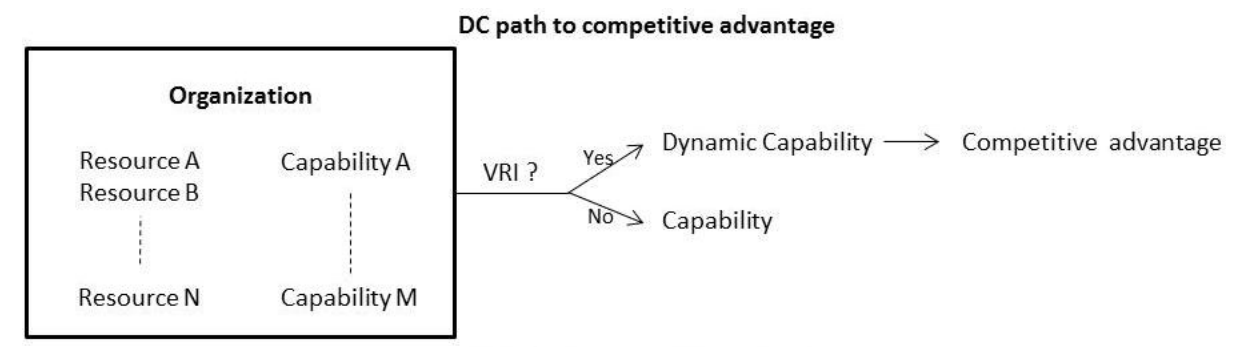

RVB path to competitive advantage

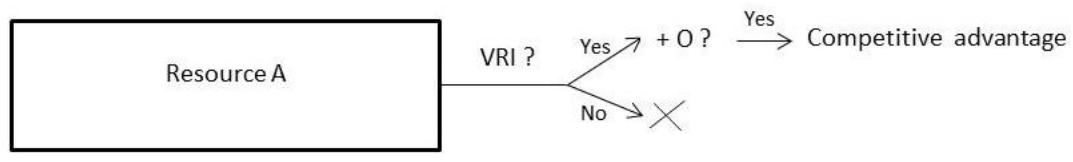

Figure 1. RBV / DC paths to competitive advantage.

advantage, firms need VRIO resources. The unit of analysis is the resource. From the DC viewpoint, capabilities at the origin of competitive advantage need to be VRI (the "O" is the capability) and so the unit of analysis is organization or capability (Figure 1). Which of these is dominant? To answer this question we formulate the research question: Do firms with competitive advantage have VRIO resources or VRI capabilities?

\section{The current literature}

Although RBV in general and DC in particular have become influential and frequently cited theories in relation to theoretical developments in the area of strategy (Kraaijenbrink et al., 2010; Lockett et al., 2009), few studies investigate in detail how resources/capabilities are developed over time (Laamanen and Wallin, 2009; Newbert, 2007), and particularly in more traditional industries where there are different conditions and constraints (Easterby-Smith et al., 2009). The resources required for competitive advantage often are not readily identifiable and some studies empirically test the most identifiable, but probably not the most important ones (Lockett et al., 2009) .

The literature supports the need for qualitative studies to understand the origins of capabilities (Felin and Nicolai, 2009), to understand why companies choose a certain path of development (Laamanen and Wallin, 2009), how firms introduce dynamic components into existing capabilities (Shamsie et al., 2009), how organizations develop the capabilities/resources that are the source of their competitive advantage (Ambrosini and Bowman, 2009; Easterby-Smith et al., 2009). This is particularly important in slowly changing environments with infrequent external shocks (Vergne and Durand, 2011), in smaller companies where resource bundles are less complex (Lockett et al., 2009), and special attention is needed for capabilities' implementation (Pablo et al., 2007) and for decision-making and interactions among individuals (Felin and Nicolai, 2009). It is especially important to examine how capabilities are developed and to test to what extent they are VRIO, for example, according to the RBV, whether capabilities are enablers of competitive advantage (Arend and Bromiley, 2009).

\section{METHODOLOGY}

We adopt the definition of firm competitive advantage as creating more economic value than a marginal competitor (Peteraf and Barney, 2003) that achieves only break-even. A firm has competitive advantage if it systematically achieves net profits. Resources are defined as inputs, and capabilities are defined as intermediary outputs between resources and competitive advantage. Thus, to answer our research question, we need to identify which resources/capabilities the firm possesses. Showing how they are developed over time adds to the literature, and allows a more comprehensive view of the phenomenon. In relation to capabilities, understanding how they are developed allows a better understanding of the resources they exploit. We therefore chose an inductive case study (Yin, 2009).

The case study type can be described as theory building (Eisenhardt, 1989; Glaser and Strauss, 1967; Lee, 1999; Lee et al., 1999) and falls within the logic of contemporary description of recent events (Eisenhardt and Graebner, 2007). The research is mainly inductive (Hartley, 2004), based on data analysis to explore the phenomenon of interest, which cannot be adequately explained by the theory.

\section{Data sources and data collection}

Data were collected from four main sources (Table 1). Data were collected between January and July 2010. All data were filed and cataloged in a database. Following the interviews, some respondents were contacted again for clarifications. The interviews were conducted at the firm's facilities and lasted between $40 \mathrm{~min}$ and $1 \mathrm{~h}$ and $40 \mathrm{~min}$. Interviews were recorded and transcribed. In the interview with the head of the firm, we used an adaptation of the critical incident technique (Chell, 2004). The main question driving this interview was "what were the major strategic moves made by the firm?" Although this technique can result in information bias due to cognitive problems on the part of the respondent, it reflects the thinking of the organization's leader, who, in a medium sized firm, is the main decision maker. 
Table 1. Data sources.

\begin{tabular}{lcl}
\hline Source & Number & Example \\
\hline Interviews & 13 & Managers, directors \\
Internal records & 57 & Sales reports, financial reports, human resources reports \\
Direct observations & 5 & Manufacturing processes; informal meetings; employees outside their working context \\
Press articles & 20 & Press releases; interviews \\
\hline
\end{tabular}

Table 2. Quality of the research process.

\begin{tabular}{|c|c|c|c|}
\hline Tests & Case study tactics & Research phase & Tactics used \\
\hline \multirow{4}{*}{ Construct validity } & $\begin{array}{l}\text { To use multiple sources } \\
\text { of evidence (Yin, 2009; } \\
\text { Eisenhardt, 1989). }\end{array}$ & Data collection & $\begin{array}{l}\text { Semi-structured interviews; internal records; direct } \\
\text { observations; press articles. } \\
\text { Data sources were triangulated aiming to reinforce the } \\
\text { feasibility of their contents. }\end{array}$ \\
\hline & $\begin{array}{l}\text { To establish a chain of } \\
\text { evidence (Yin, 2009). }\end{array}$ & Data collection & $\begin{array}{l}\text { We respected the sequence: case-study questions; } \\
\text { protocol; data-bases; and final report. } \\
\text { The case-study report was with reference to the data } \\
\text { sources from the database. }\end{array}$ \\
\hline & $\begin{array}{l}\text { Revision of case study } \\
\text { reports (Yin, 2009). }\end{array}$ & Composition & $\begin{array}{l}\text { The case study was subject of a draft report for review } \\
\text { firm staff and also by industry experts. }\end{array}$ \\
\hline & $\begin{array}{l}\text { Codification process } \\
\text { and revision (Miles and } \\
\text { Huberman, 1984) }\end{array}$ & Data analysis & We used a blind coder to revise our coding process. \\
\hline External validity & $\begin{array}{l}\text { To use case study } \\
\text { protocol (Yin, 2009). }\end{array}$ & Data collection & We elaborated a protocol. \\
\hline Feasibility & $\begin{array}{l}\text { To use case study } \\
\text { databases (Yin, 2009). }\end{array}$ & Data collection & $\begin{array}{l}\text { It was developed and included the classification of all } \\
\text { the pieces of evidence, including the transcription of all } \\
\text { interviews. }\end{array}$ \\
\hline
\end{tabular}

Internal documentation and direct observation constituted sources of data to triangulate the information provided by respondents and thus control for retrospective bias. We conducted five direct observations of specific inter- and intra-team problem solving situations, and of the work methodologies in production. Employees were observed outside the work context but within the company, in order to better understand the informal relationships that existed.

In order to assure the quality of the research process, we followed the tactics summarized in Table 2.

\section{Research setting and case}

Since the 1970s Portugal has been an important player in the international footwear industry. In the 1970s and 1980s, the industry grew based on Portuguese low labor costs. In the 1990s, there was a relocation of large series productions to the Asian countries. By the 2000s, footwear had become an important fashion accessory, and consumers were showing preferences for distinctive and different products. The industry has evolved towards flexible production of small series of distinctive fashion footwear, with very fast lead times. In this new era, factors such as flexibility, rapid response, market knowledge, design and marketing have been crucial for a firm's success. New business models are essential for companies to survive and succeed. Our study case is a medium sized Portuguese footwear manufacturer (ABREUS), which has recently developed a new business model. The Portuguese footwear industry fits with what Eisenhardt and Martin (2000) describe as moderate dynamic markets. By selecting a medium sized company, we chose a context where resources and capabilities bundles are less complex. ABREUS was founded by two brothers in 1994. In the industrial district (Felgueiras), it is acknowledged to be a company that is "doing a good job". In 2007, ABREUS felt the force of changes in customer behavior when they placed their large orders in other markets. In 2007 some major ABREUS customers went elsewhere or reduced their purchases from ABREUS, which accelerated the strategic reorientation of the firm Table 3 shows the major economic and financial indicators of the firm over the last years. The ABREUS brand is GOLDMUD which was established in 2006. From the start, the brand was managed by a new firm owned jointly by Miguel Abreu (the firm's main leader), his father and his uncle, the owners of ABREUS. Currently, ABREUS's source of competitive advantage lies in its 
Table 3. Major economic and financial indicators (thousand $€$ ).

\begin{tabular}{lcccccc}
\hline \multirow{2}{*}{ Financial indicators } & \multicolumn{7}{c}{ Year } \\
\cline { 2 - 7 } & $\mathbf{2 0 0 5}$ & $\mathbf{2 0 0 6}$ & $\mathbf{2 0 0 7}$ & $\mathbf{2 0 0 8}$ & $\mathbf{2 0 0 9}$ & $\mathbf{2 0 1 0}$ \\
\hline Sales & 8.037 & 11.263 & 10.501 & 8.819 & 7.974 & 7.135 \\
Net profits & 86 & 94 & 87 & 23 & 24 & 21 \\
Assets & 3.332 & 3.927 & 5.541 & 5.897 & 5.643 & 6.441 \\
Equity & 701 & 715 & 952 & 976 & 1.109 & 985 \\
\hline
\end{tabular}

Source: company internal records (ABREUS, 2005 to 2010).

ability to create value for its customers by developing new products, coupled with the ability to produce them with reasonable quality, at reasonable cost and on time. That is, the firm creates value by developing solutions for difficult and distinctive shoes. The milestones leading to ABREUS's current situation are identified in Table 4.

\section{DATA ANALYSIS}

\section{ABREUS capabilities development}

The changing process of ABREUS was originated from a combination of two circumstances that occurred between 2006 and 2007. In 2006, the company launched its brand. In 2007, two of its major customers significantly reduced the volume of their purchases. In 2008, their purchases reduced again.

The period from 2006 to 2009 corresponds to a phase of significant investment in human resources and technology development. In 2005, the development department employed four. In late 2009, the structure was led by Miguel Abreu and was composed of 14 people, including 4 modelers and a stylist. In this period, the firm bought several new Computer-aided design (CAD) stations.

Between 2008 and 2009, the company made several investments to adapt the plant building including increasing the physical space dedicated to new product development (NPD), creating a specific area to install a samples production line separate from production. During this period ABREUS acquired the necessary equipment to create this line, the need for which had become evident if the company was to be able to respond to increasing requests from GOLDMUD as well as from new customers with different needs from the firm's traditional ones.

The human resources dedicated to NPD combined with the new equipment, provided increased capacity for the production of samples. It enabled ABREUS to respond appropriately and to respect clients' deadlines:

"... Now they have a good capacity of producing samples, at the very best level. It is pretty good..." (Consultant at Technological Centre).

This capability to produce samples and prototypes is essential for good customer service in relation to NPD. However, there is also a need for the capability to interpret customers' ideas and to find innovative solutions, in relation to materials and construction or finishing. ABREUS' NPD is distinguished by the ability to suggest new solutions:

"... Today we often suggest new things to the customer. We do more than the client initially wants. We suggest many things, and it makes a big difference. Firstly puts us at a level that allows us to escape the discussion of price as a priority ..." (Miguel Abreu)

This approach to value creation by proposing new materials, and/or new constructions, had been dominant in the firm for 2 to 3 years at the time of our study. The ability to propose different solutions begins with the capacity to interpret customers' ideas and needs, so knowledge about customers and the types of shoes they buy is important for the development phase. In the initial developments for a particular client, ABREUS may not be fully aware of specific needs. It makes efforts to understand better what the customer wants through conversations with the client or his representative or through surveys (for example the Internet). The modeling team does not have a set guideline about what to do to better understand the development context. Modelers are allocated to specific costumers and it is their own responsibility to manage the process of interpreting their specific needs.

The company's decision to launch its own brand had a major impact on ABREUS's current capability in NPD, in particular because the new brand:

1. Was seen not as a brand belonging to the firm but as a new customer: From the outset, GOLDMUD was positioned as a very demanding customer and contributed to improvement in the factory's quality levels:

"... GOLDMUD is a very demanding customer! It has to be and pushes everyone to be more demanding too. You cannot close your eyes and non-quality products cannot pass up ... every one pair is seen under the microscope" (Head of planning department).

GOLDMUD's product development is conducted jointly 
Table 4. Major decisions relevant to the firm's current situation.

\begin{tabular}{|c|c|c|c|}
\hline Year & Decision/fact & Rational & Impact on actual capability \\
\hline 1995 & Integration of modeling & To start the NPD & Minimum \\
\hline 1997 & Admission of Miguel Abreu & $\begin{array}{l}\text { To reinforce the commercial } \\
\text { department }\end{array}$ & $\begin{array}{l}\text { He was the great mentor and leader in the } \\
\text { development process of new capability.. }\end{array}$ \\
\hline 1998 & Exhibition at MOCAP & Search for new costumers & Minimal \\
\hline 2000 & $\begin{array}{l}\text { Beginning of the relationship } \\
\text { with Grupo Sonae }\end{array}$ & $\begin{array}{l}\text { Creating a new business model of } \\
\text { agency. }\end{array}$ & $\begin{array}{l}\text { Business that is in its final stage of the life } \\
\text { cycle. Minimum. }\end{array}$ \\
\hline $\begin{array}{l}2000 \text { to } \\
2006\end{array}$ & $\begin{array}{l}\text { Integration of several } \\
\text { mounting systems }\end{array}$ & Meet different customer needs & $\begin{array}{l}\text { Allows the vertical integration of the production } \\
\text { of a greater variety of types of shoes. }\end{array}$ \\
\hline 2004 & $\begin{array}{l}\text { Acquisition of a automatic } \\
\text { cutting machine }\end{array}$ & $\begin{array}{l}\text { Adjust the production structure to } \\
\text { smaller production series and to } \\
\text { increase the production capacity of } \\
\text { samples. }\end{array}$ & $\begin{array}{l}\text { Increased production of samples and a series } \\
\text { of smaller dimension }\end{array}$ \\
\hline 2006 & $\begin{array}{l}\text { Acquisition of a second } \\
\text { assembly and finishing line }\end{array}$ & Raise on the production capacity & Greater flexibility \\
\hline 2006 & Creation of GOLDMUD & $\begin{array}{l}\text { Reduce dependence on } \\
\text { intermediate customers. Increasing } \\
\text { the value added. }\end{array}$ & $\begin{array}{l}\text { Strengthening the structure of NPD. Higher } \\
\text { levels of competence in NPD and production. } \\
\text { Raise of the production flexibility. }\end{array}$ \\
\hline 2007 & Loss of important costumers & $\begin{array}{l}\text { Costumers that had price as key } \\
\text { buying factors }\end{array}$ & $\begin{array}{l}\text { Greater openness to pursuing a different } \\
\text { strategy }\end{array}$ \\
\hline 2007 & Exhibition at MICAM & Raise the notoriety of the brand & $\begin{array}{l}\text { New customers with different needs from } \\
\text { traditional ones. }\end{array}$ \\
\hline 2007 & Subcontracting CTCP & Support the process of change & $\begin{array}{l}\text { Changing the culture, improving the quality } \\
\text { and flexibility. }\end{array}$ \\
\hline 2008 & $\begin{array}{l}\text { Creation of reverted } \\
\text { mocassin }\end{array}$ & $\begin{array}{l}\text { Develop a distinctive solution for } \\
\text { GOLDMUD }\end{array}$ & $\begin{array}{l}\text { Patent protected, gave the experience and } \\
\text { confidence that allows the company to easily } \\
\text { develop new assembly systems. }\end{array}$ \\
\hline 2008 & Expansion of facilities & $\begin{array}{l}\text { Creating space for the NPD and } \\
\text { improve image with new customers. }\end{array}$ & $\begin{array}{l}\text { Allowed the creation of a sample production } \\
\text { line. }\end{array}$ \\
\hline 2009 & $\begin{array}{l}\text { Investment in a production } \\
\text { line for samples }\end{array}$ & $\begin{array}{l}\text { Improve the capacity of response to } \\
\text { samples }\end{array}$ & $\begin{array}{l}\text { Increased capacity of NPD, larger installed } \\
\text { capacity of samples and faster response in } \\
\text { sending samples to customers. }\end{array}$ \\
\hline
\end{tabular}

together by the stylist and ABREUS's technical team. A GOLDMUD collection includes very diverse constructions, distinctive finishes, innovations, different designs and novel parts. All of this variety forces the technical team to extend its skills. They frequently learn from leather or finishing materials suppliers to accumulate the knowledge needed to create the models for the brand.
This accumulated technical knowledge contributes to subsequent NPD for other customers. Learning from suppliers has become very important for the firm. As Miguel Abreu said:

"... It is necessary to acquire more knowledge and what we need to do is learning. I have to rely on the relevant 


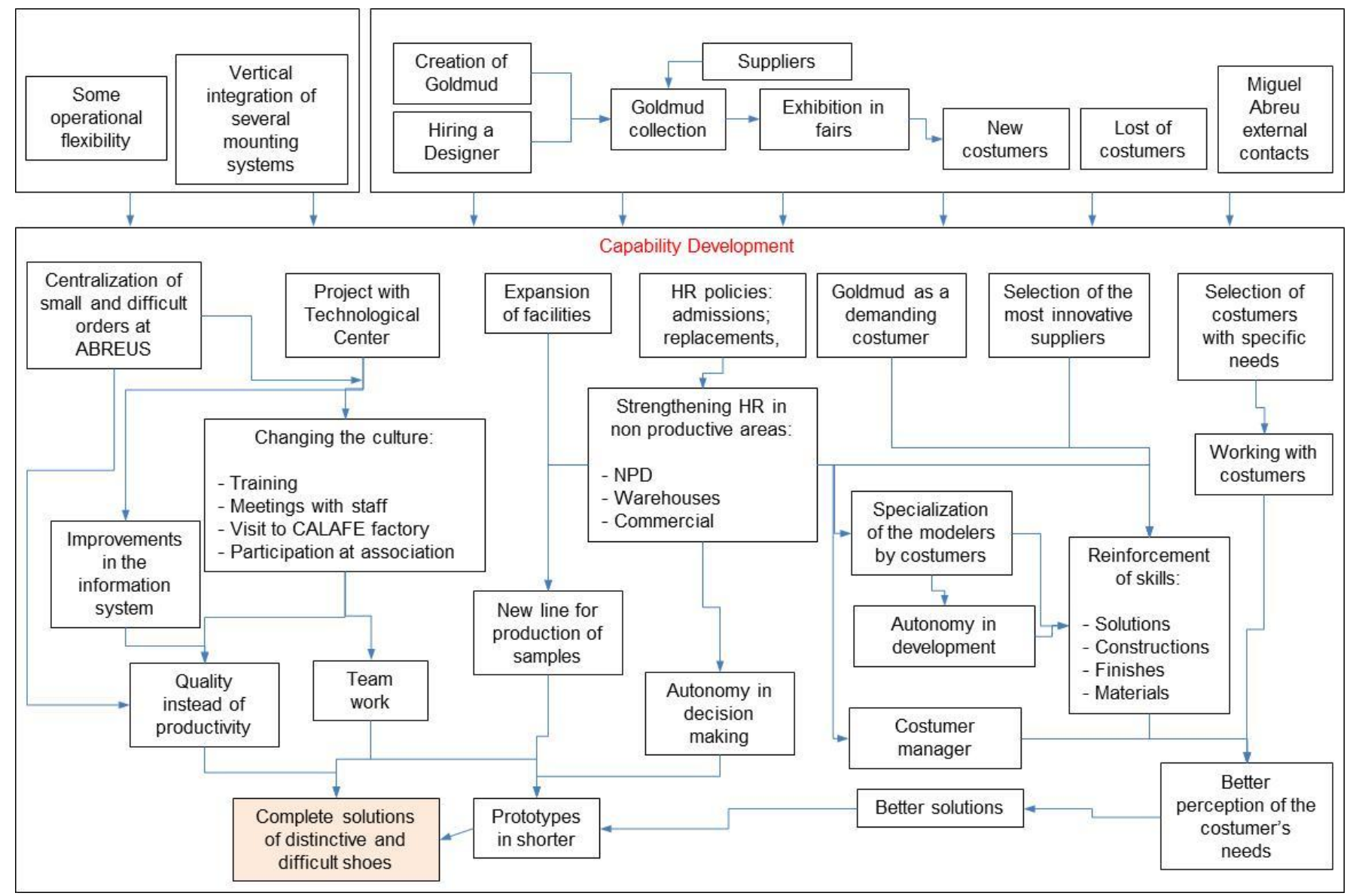

Figure 2. Logical model of NPD development.

people. I know whom to call, people I can rely on ..."

2. The new brand has led to the development of a new shoe assembly process: With GOLDMUD, Miguel Abreu tried to "do something different". His idea was so different, that the company had to develop a new system for assembling shoes, called "reverted moccasin". Miguel Abreu asked for a different mounting, flexible and comfortable, and since the factory was familiar with production of "moccasins", the team was able to create this new mounting system, which leveraged staff skills in the direction the leader intended.

Once the new mounting system was developed, it was decided that it would only be used in GOLDMUD shoes. Several customers have requested the new construction, but ABREUS has not given in to these requests. The experience of developing the "reverted moccasin" allowed ABREUS to develop new mounting systems for specific customers.

3. The brand has given the company visibility and opened the firm's doors to new customers with different needs: With the creation of GOLDMUD, the company resumed exhibitions at trade fairs, although only the most important footwear fairs. These exhibitions brought new customers, especially those with similar product concepts, and ABREUS became a partner in the development and production of their new products. The emergence of new customers and the disappearance of old ones, created an opportunity for changes to the whole NPD area in terms of human resources and its physical space and equipment.

Figure 2 is a logic model (Yin, 2009) depicting how ABREUS created the capability to develop solutions for difficult and distinctive shoes.

\section{DISCUSSION}

Having identified the capability underlying the company's competitive advantage and collecting the data needed to understand how it was created over time, we want to test input resources for VRIO and the capability for VRI. The analysis starts from the suggestions in Kraaijenbrink et al. (2010) and Locket et al. (2009), which are compatible with the proposal in Peteraf and Barney (2003), for example, a model in which competitive advantage stems from how the firm integrates a set of critical resources. Kraaijenbrink et al. (2010) also suggest that a distinction 
Table 5. VRIO analysis of NPD.

\begin{tabular}{lccc}
\hline Resource & Valuable & Rare & Inimitable \\
\hline Reverted Mocassin & - & + & + \\
Creative Design & - & + & - \\
Technical Design & - & + & + \\
Technical Skills & - & - & - \\
Technology relationship with the cluster & & & + \\
New Product Development & + & + & + \\
\hline
\end{tabular}

Source: Author analysis.

should be made between resources and capabilities, while Locket et al. (2009) suggest that researchers should invest in understanding the functionality of resources and how they relate to the markets for products/services in which companies compete.

Thus, capability is the result of how the company integrates a particular set of critical resources. Individual resources are the inputs to the capability. The capability is the "output" of how the company integrates these critical resources to the capability corresponding to the organization, that is, the "O" of the model VRIO (Barney, 1997).

The content analysis identified a set of resources and capabilities that are the capability's inputs (Table 5). There were some problems related to what Kraaijenbrink et al. (2010) call the impracticality of defining resources, which stems from the fact that the definitions in the literature (Amit and Schoemaker, 1993; Barney, 1991, 2002; Wernelfelt, 1984) are ambiguous, allowing almost anything to be framed as a resource (Steen, 2010). For example, should "relationship with the cluster" be considered a resource or a capability? "Relationship with the cluster" surely is the result of how the firm, over time, develops the integration of other basic resources and, according to the methodology used in this study, should be considered a capability. If "relationship with the cluster" is a capability, this raises another question, which enters the domain of the hierarchy of capabilities.

Since "relationship with the cluster" is an input to the analyzed capability, then the analyzed capability, for example according to Collis (1994), must be a second order capability. To prevent a discussion on the hierarchy of capabilities, which is not the purpose of this study, we assume that:

(1) "Inputs" are isolated resources or capabilities that are integrated to produce an output capability;

(2) "Intermediary output" is the capability under analysis.

Having identified the capability's inputs, we analyzed each resource individually, primarily in terms of value and rarity and subsequently in terms of their inimitability. Resources that were not identified as rare were not analyzed through the prism of inimitability. To investigate inimitability of those resources considered rare, we conducted a content analysis of the characteristics that create barriers to imitability (Barney, 1991; Peteraf and Barney, 2003).

Our first finding is that, individually, none of the resources is valuable. This is consistent with the DC literature (Katkalo et al., 2010).

In the firm's business model, the "reverted moccasin" on its own is not valuable because it needs to be coupled to other resources such as design, to be transformed into a shoe that creates value. Property rights on the "reverted moccasin" determine that this resource cannot be imitated, defining it as a unique and rare solution.

Design falls into two major phases. The first phase relates to the creative process, which is related to the concept of the new product - called creative design. This is where the development and selection of different themes for the collections and the "scribbles", which correspond to the drawings of the designers, are performed. At ABREUS, this resource is applied only at GOLDMUD. In this business model, creative design alone does not constitute a valuable resource because the company needs to have other basic resources, such as technical design and technology among others, to turn the creative design into outputs that allow the exploitation of opportunities.

The creative design associated with GOLDMUD is rare in the sense that the brand has an identity that is distinct from any other. However, having defined the concept of the brand and developed the first collections that created its identity, creative design with the features of GOLDMUD became easily imitable. That is, it would be relatively easy for another company or designer not connected to ABREUS, to develop a creative design for a shoe that imitates the spirit of GOLDMUD.

The second phase of design is technical design, where the concept is translated from the creative design into a new product (design model), the soles are developed, and the construction and selection of materials is agreed. It reflects how the company is able to understand the needs of a specific client with a new product concept (for example, a picture of a shoe or a draft design), and the ability to create new products based on an individual client's needs. Technical design on its own is not 
Table 6. NPD's coding - Inimitability.

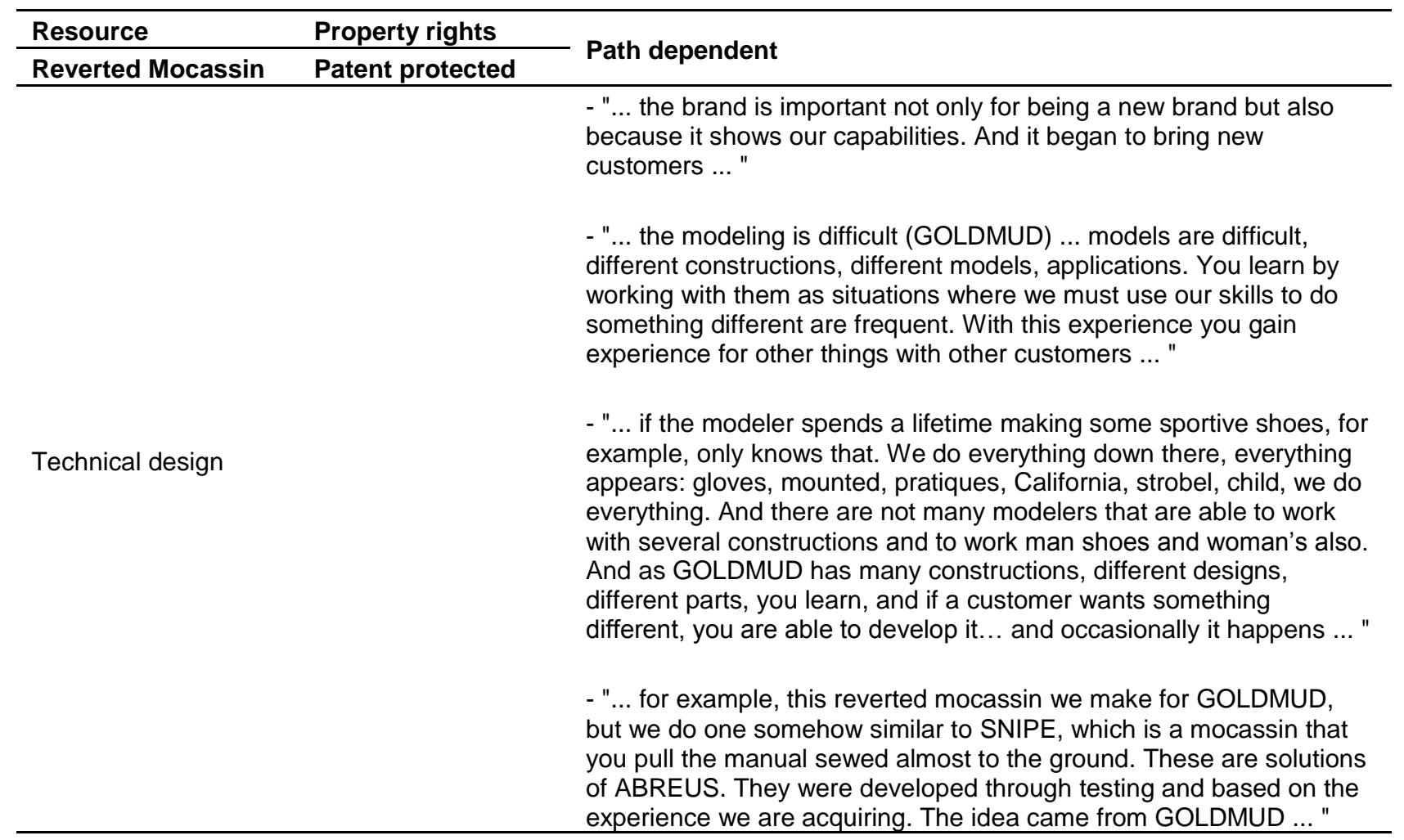

valuable. To take advantage of this resource, for example, the firm would need to transform its input into a technical model which could be produced in an industrial environment and subsequently to produce or outsource its production. This is a relatively rare resource in the industry.

According to many experts we consulted, only a minority of Portuguese footwear firms posses this resource at this level of development. The technical design at ABREUS has the characteristics that it is path dependent; for example, new constructions developed and suggested to customers result in adaptations to "reverted moccasin". Past experience with developments at GOLDMUD influence the firm's technical design in relation to high standards and finishing concepts and materials, where experience with the firm's original brands benefits ABREUS (Table 6).

Technical skill reflects the team's knowledge and allows the design to be transformed into a testable model. It involves CAD knowledge, as well as the knowledge needed to test new models and the sequence of productive operations needed to minimize production costs based on the ability to mitigate technical modeling and potential quality problems at an early stage. The technical skill in NPD on its own is not valuable because without the right technologies or without a corporate culture already geared to flexibility and quality, performance in NPD would be substantially lower. Technology for the development of new products includes CAD systems, leather cutting machines and the production machinery to produce samples and to test new models. Technology alone cannot be valuable because the proper functioning of these devices depends largely on the operator's technical skills.

The relationship with the cluster essentially captures the firm's predisposition to work with the most innovative suppliers and adopt new materials and finishing solutions. Without adequate technical capacity, or the technology needed to turn final designs using innovative solutions into tested models, the relationship with the cluster does not allow the exploitation of opportunities or the mitigation of the effects of possible threats.

The analysis on each of the NPD capability resources shows that, individually, none of them passes VRIO test for competitive advantage. ABREUS's competitive advantage lies in how the firm is organized in order to integrate the six resources. The NPD capability represents the way (the organization) the firm integrates the resources "reverted moccasin", creative and technical designs, technical skills, technology and relationship with the cluster. In the ABREUS business model this capability is valuable, because it allows the firm to generate outputs, exploit opportunities and mitigate threats, more precisely it allows the offer of complete shoe solutions that are distinctive and difficult to manufacture. The value of this capability is strengthened by its combination with other 
resources, for example, production technology, operational flexibility, and product quality. Those resources and capabilities already existed at ABREUS and when improved, allow ABREUS to integrate vertically the manufacturing of the shoes developed.

Since the company's NPD capability is the result of the integration of six resources, its imitability by competitors is made more difficult due to causal ambiguity (Barney, 1991). Indeed, the more complex the capability, for example, because it includes a larger set of resources, the less evident it becomes, even to the firm and the less easy it is to understand the origins of competitive advantage.

\section{Conclusion}

The previous discussion shows that the company has one capability (development of new products) that passes VRI DC test. The inputs (resources) of the capability were tested according to VRIO in the RBV. None passed the test; particularly due to the valuable issue (none of the input resources/capabilities is, separately, valuable, as the firm needs some organization to take full advantage of them). This is consistent with previous RBV literature. It can be concluded that, in this case, the competitive advantage stems from a VRI capability and not from VRIO resources. The complexity of the analyzed capability makes it socially complex, contributing to the reinforcement of its inimitable characteristic. This finding is of the outmost relevance for managers. The more complex capabilities that lead to competitive advantage are, in terms of bundles of resources they integrate, the more difficult for competitors is to copy them, allowing competitive advantage to be sustained for longer periods of time.

From a theoretical point of view, this article contributes to the RBV literature in general and to work on DC in particular based among other reasons, on the findings related to VRI DC vs. VRIO RBV:

(a) Lack of examination of the VRIO conditions is a limitation in the previous literature.

(b) In finding how the capability was developed, and analyzing the underlying micro-dynamics of organizational activity, this article makes an important contribution by addressing an important critique of the RBV, which is that it does not address how resources/capabilities are transformed into competitive advantage.

(c) By defining capabilities as the way that the company integrates a bundle of resources, the research defines capabilities as an intermediate output between resources and competitive advantage, contributing to filling a gap in the resource literature, and resolving some of the confusion surrounding the use of the terms resources, capabilities, skills, and assets to refer to the same thing. The main limitation of this article is that the findings cannot be generalized because we study only one firm.
To confirm whether or not these findings are generalizable, we need more qualitative and/or quantitative studies.

\section{REFERENCES}

Adner R, Helfat CE (2003). Corporate effects and dynamic managerial capabilities. Strat. Manage. J. 24(10):1011-1025.

Ambrosini V, Bowman C (2009). What are dynamic capabilities and are they a useful construct in strategic management? Int. J. Manag. Rev. 11(1):29-49.

Ambrosini V, Bowman C, Collier N (2009). Dynamic capabilities: an exploration of how firms renew their resource base. Brit. J. Manage. 20(S1):S9-S24.

Amit R, Schoemaker PJH (1993). Strategic assets and organizational rent. Strat. Manage. J. 14(1):33-46.

Arend RJ, Bromiley P (2009). Assessing the dynamic capabilities view: spare change, everyone? Strateg Organ. 7(1):75-90.

Barney JB (1991). Firm resources and sustained competitive advantage. J. Manage. 17(1):99-120.

Barney JB (1995). Looking inside for competitive advantage. Acad. Manag. Exec. 9(4):49-61.

Barney JB (1997). Gaining and Sustaining Competitive Advantage. Addison-Wesley: Reading, MA.

Barney JB (2001). Is the resource-based "view" a useful perspective for strategic management research? Yes. Acad. Manage Rev. 26(1):4156.

Barney JB, Wright $P(1998)$. On becoming a strategic partner: The role of human resources in gaining competitive advantage. Hum. Resour. Manage. 37(1):31-46.

Barney JB, Zajac EJ (1994). Competitive organizational behavior: Toward an organizationally-based theory of competitive advantage. Strat. Manage. J. 15(S1):5-9.

Barreto I (2010). Dynamic capabilities: A review of past Research and an agenda for the future. J. Manage. 36(1): 256-280.

Bowman C, Ambrosini V (2007). Identifying valuable resources. Eur Manag. J. 25(4):320-329.

Cavusgil E, Serggie SH, Talay MB (2007). Dynamic capabilities view: Foundations and research agenda. J. Market Theor. Pract. 15(2):159-166.

Chell E (2004). Critical Incident Technique. In Essential Guide to Qualitative Methods in Organizational Research. Cassel C, Symon G (eds.), SAGE Publications: London.

Collis DJ (1994). Research Note: How Valuable are Organizational Capabilities? Strat. Manage J. 15(S1):143-152.

Collis DJ, Montgomery CA (1995). Competing on resources: strategy in the 1990s. Harvard Bus Rev. 73:118-128.

Collis DJ, Montgomery CA (2008). Competing on resources. Harvard Bus. Rev. 86(7,8):140-150.

Danneels E (2002). The dynamics of product innovation and firm competences. Strat. Manage. J. 23(12):1095-1121.

Di Stefano G, Peteraf MA, Verona G (2010). Dynamic capabilities deconstructed: a bibliographic investigation into the origins, development, and future directions of the research domain. Ind. Corp Change 19(4):1187-1204.

Dierickx I, Cool K (1989). Asset stock accumulation and sustainability of competitive. Manage. Sci. 35(12):1504-1513.

Døving E, Gooderham PN (2008). Dynamic capabilities as antecedents of the scope of related diversification: the case of small firm accountancy practices. Strat. Manage. J. 29(8):841-857.

Easterby-Smith M, Lyles MA, Peteraf MA (2009). Dynamic capabilities: current debates and future directions. Brit. J. Manage. 20(S1):S1-S8.

Eisenhardt KM (1989). Building theory from case study research. Academy of Management. Acad. Manag. Rev. 14(4):532-550.

Eisenhardt KM, Graebner ME (2007). Theory building from cases: opportunities and challenges. Acad. Manage. J. 50(1):25-32.

Eisenhardt KM, Martin JA (2000). Dynamic capabilities: What are they? Strat. Manage. J. 21(10/11):1105-1121.

Felin T, Nicolai JF (2009). Organizational routines and capabilities: Historical drift and a course-correction toward microfoundations. 
Scand J. Manag. 25:157-167.

Fiol CM (1991). Managing culture as a competitive resource: An identity-based view of sustainable competitive advantage. J. Manage 17(1):191-211.

Glaser B, Strauss AL (1967). The Discovery of Grounded Theory: Strategies for Qualitative Research. Aldine de Gruyter: New York.

Hartley J (2004). Case Study Research. In Essential Guide to Qualitative Methods in Organizational Research. Cassel C, Symon G (eds.), SAGE Publications Ltd: London.

Helfat C, Finkelstein S, Mitchell W, Peteraf M (2007). Dynamic Capabilities: Understanding Strategic Change in Organizations. Blackwell: Oxford, UK.

Katkalo VS, Pitelis CN, Teece DJ (2010). Introduction: on the nature and scope of dynamic capabilities. Ind. Corp Change 19(4):11751186.

Kay N (2010). Dynamic capabilities as context: the role of decision, system and structure. Ind. Corp Change 19(4):1205-1223.

Kraaijenbrink J, Spencer JC, Groen AJ (2010). The Resource-Based View: A review and assessment of its critiques. J. Manage. 36(1):349-372.

Laamanen T, Wallin $\mathrm{J}$ (2009). Cognitive dynamics of capability development paths. J. Manage. Stud. 46(6):950-981 .

Lado AA, Wilson MC (1994). Human resource systems and sustained competitive advantage: A competency-based perspective. Acad. Manag. Rev. 19(4):699-727.

Lee TW (1999). Using Qualitative Methods to Organize Res. SAGE: Newbury Park, CA.

Lee TW, Mitchell TR, Sablynski CJ (1999). Qualitative research and vocational psycol. J. Vocat. Behav. 55(2):161-187.

Liao J, Kickul JR, Ma H (2009). Organizational dynamic capability and innovation: an empirical examination of internet firms. J. Small Bus. Manage. 47(3):263-286.

Lockett A, Thompson S, Morgenstern U (2009). The development of the resource-based view of the firm: a critical appraisal. Int. J. Manag. Rev. 11(1):9-28.

Makadok R (2001). Toward a synthesis of the resource-based and dynamic-capability views of rent creation. Strat. Manage. J. 22(5):387-401.

Miles M, Huberman AM (1984). Qualitative data analysis. SAGE: Newbury Park.

Miller D, Shamsie J (1996). The resource-based view of the firm in two enviroments: The Hollywood film studios from 1936 to 1965 . Acad. Manage. J. 39(3):519-543.

Morgan NA, Vorhies DW, Mason CH (2009). Market orientation, marketing capabilities, and firm performance. Strat. Manage. J. 30(8):909-920.

Newbert SL (2007). Empirical research on the resource-based view of the firm: an assessment and suggestions for future research. Strat. Manage. J. 28(2):121-146.

Newbert SL (2008). Value, rareness, competitive advantage, and performance: a conceptual-level empirical investigation of the resource-based view of the firm. Strat. Manage. J. 29(7):745-768.

Pablo AL, Reay T, Dewald JR, Casebeer AL (2007). Identifying enabling and managing dynamic capabilities in the public sector. J. Manage. Stud. 44(5): 687-708.

Pan SL, Tan BCC, Huang J, Poulsen B (2007). The development paths of non-strategic capabilities. Eur. Manag. J. 25(5):344-358.
Penrose ET (1959). The Theory of the Growth of the Firm (3 ed.). John Wiley Sons: New York.

Peteraf MA, Barney JB (2003). Unraveling the Resource-Based tangle. Manag. Decis. Econ. 24(4):309-323.

Priem RL, Butler JE (2001a). Is the resource-based "view" a useful perspective for strategic management research? Acad. Manage Rev. 26(1):22-40.

Prieto IM, Revilla E, Rodríguez-Prado B (2009). Building dynamic capabilities in product development: How do contextual antecedents matter? Scand J. Manag. 25(3):313-326.

Reed R, DeFillipi RJ (1990). Causal ambiguity, barriers to imitation, and sustainable competitive advantage. Acad. Manag. Rev. 15(1):88-102.

Shamsie J, Martin X, Miller D (2009). In the old, in the new: capabilities, strategies, and performance among the Hollywood studios. Strat. Manage. J. 30(13):1440-1452.

Steen $J$ (2010). Actor-network theory and the dilemma of the resource concept in strategic management. Scand J. Manag. 26:324-331.

Teece DJ, Pisano G, Shuen A (1997). Dynamic capabilities and the strategic management. Strat. Manage. J. 18(7):509-533.

Vergne JP, Durand R (2011). The path os most persistence: An evolutionary perspective on path dependence and dynamic capabilities. Organ. Stud. 32(3):365-382.

Wang CL, Ahmed PK (2007). Dynamic capabilities: a review and research agenda. Int. J. Manag. Rev. 9(1):31-51.

Wills-Johnson N (2008). The networked firm: a framework for RBV. J. Manag. Dev. 27(2):214-224.

Winter SG (2003). Understanding dynamic capabilities. Strat. Manage. J. 24(10): 991-995.

Wu L (2010). Applicability of the resource-based and dynamic-capability views under environmental volatility. J. Bus Res. 63(1):27-31.

Yin RK (2009). Case Study Research: Design and Methods (4 ed.). SAGE Inc.: Thousand Oaks.

Zahra S, Sapienza H, Davidsson P (2006). Entrepreneurship and dynamic capabilities: a review, model and research agenda. J Manage. Stud. 43(4):917-955.

Zollo M, Winter SG (2002). Deliberate learning and the evolution of dynamic capabilities. Organ Sci. 13(3):339-351. 